\title{
Adverse Event Grade Code
}

National Cancer Institute

\section{Source}

National Cancer Institute. Adverse Event Grade Code. NCI Thesaurus. Code C93711.

A coded value specifying the level of injury suffered by the subject for whom the event is reported. 